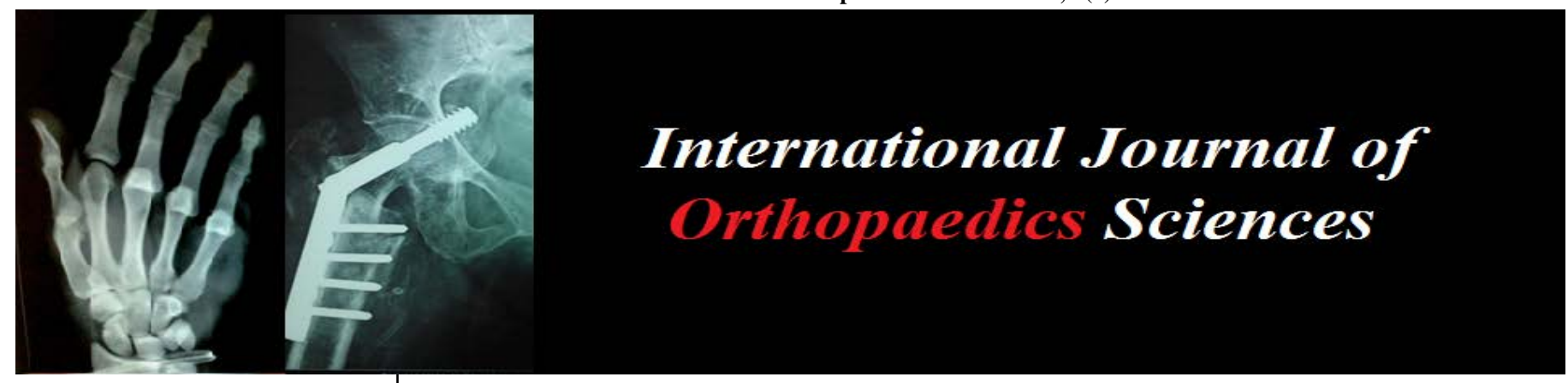

E-ISSN: 2395-1958

P-ISSN: 2706-6630

IJOS 2021; 7(4): 643-646

(C) 2021 IJOS

www.orthopaper.com

Received: 20-06-2021

Accepted: 27-07-2021

Dr. Channareddy $\mathbf{H}$

Professor, Department of

Orthopaedics, Basaveshwara

medical College and Hospital,

Chitradurga, Karnataka, India

Dr. Palakshaiah L

Professor, Department of

Orthopaedics, Basaveshwara

medical College and Hospital,

Chitradurga, Karnataka, India

Dr. Pragadeeshwaran G

Post Graduate Student,

Department of Orthopaedics,

Basaveshwara medical College

and Hospital, Chitradurga,

Karnataka, India
Corresponding Author: Dr. Channareddy $\mathrm{H}$ Professor, Department of Orthopaedics, Basaveshwara medical College and Hospital, Chitradurga, Karnataka, India

\section{Acute Achilles tendon ruptures: Surgical versus non- surgical treatment using early functional rehabilitation: A randomized controlled study}

\author{
Dr. Channareddy H, Dr. Palakshaiah L and Dr. Pragadeeshwaran G
}

DOI: https://doi.org/10.22271/ortho.2021.v7.i4i.2946

Abstract

Patients were randomized to surgical or non-surgical treatment for acute Achilles tendon rupture. All patients in both the groups underwent functional [bracing] treatment that includes early weight bearing and early range of motion exercises. The primary outcomes included calf circumference, range of motion, calf muscle strength and functional evaluation by Achilles tendon total rupture [ATRS] score at 6 and 12 months after injury. The secondary outcome is re-rupture rates and other complications.

Results: A total of 30 patients [15 patients treated operatively and 15 patients treated non-operatively] were randomized. There were 19 men and 11 women. Mean age $49.5 \pm 11.5$ years. Re-ruptures occurred in 1 patient [7\%] in the surgical group and 2 patients [13\%] in the non-surgical group [P=0.368]. The mean ATRS Score at 6 months and 12 months was 74 and 86 in the surgical group and 69 and 84 in the non-surgical group respectively. There was no statistically significant difference between 2 groups with regard to calf circumference ROM, Plantar flexion strength and ATRS Score [p=0.713, $\mathrm{p}=0.412]$. More complications occurred in the operative group, mainly related to wound and soft tissues, compared to non-operative group [15 vs 8].

Conclusion: The results of this study demonstrates no significant differences between operative and nonoperative functional treatment with regard to re-rupture rates and functional results. Early weight bearing and early ROM exercises are beneficial whether treated by surgical or non-surgical treatment. Addition of functional [Brace] rehabilitation to non-operative treatment avoids wound complications associated with surgery and is a valid alternative to surgical treatment.

Keywords: Achilles tendon, acute rupture, surgical and conservative treatment

\section{Introduction}

The Achilles tendon is the largest tendon in the human body and the most common tendon to be ruptured in the body. The symptoms of Achilles tendon rupture include pain, restricted activities of the daily living and decreased physical activity. Treatment options include operative treatment and non-operative treatment. Surgical options include open, minimally invasive and percutaneous repair of the tendon. Non-operative treatment includes cast, cast boot or splint with foot in plantar flexion.

Traditionally surgical treatment was recommended as it decreases the re-ruptures rates and improves heel rise strength compared to non-operative treatment ${ }^{[1,2]}$, although surgery related complications including wound infections scar and skin adhesions, skin and tendon necrosis and sural nerve damage are well known. The associated risks and complications have been viewed as acceptable trade off for patients and surgeons who persue surgery ${ }^{[3]}$. More recent randomized controlled studies and meta-analysis have suggested equivalent re-rupture rates and muscle strength between surgical and non-surgical treatment, if accelerated rehabilitation and early weight bearing are utilized ${ }^{[1,2,3]}$.

Early ROM and controlled loading of healing tendons has been shown to result in improved healing and outcomes in animal models and some human studies ${ }^{[4,5,6]}$, while minimizing the possibility of healing of tendon in lengthened position or re-rupture ${ }^{[4,7,8]}$.

The purpose of the present study is to compare the functional outcomes and re-rupture rates of patients with acute Achilles tendon rupture, treated by surgery in one group and non-surgical treatment in other group but use of identical functional treatment - early ROM and early weight bearing in both the groups. 


\section{Materials and Methods}

A total of 30 patients with acute Achilles tendon rupture included in this Randomized controlled study. This study was conducted at Basaveshwara Medical College and Hospital between 2017 and 2021. All the patients with acute midsubstance tear of Achilles tendon who met the inclusion criteria and gave consent for the study were included. The inclusion and exclusion criteria are given below.

Table 1: Eligibility Criteria

\begin{tabular}{|c|c|}
\hline Inclusion Criteria & Exclusion criteria \\
\hline Acute complete ruptures of TA & Partial ruptures \\
\hline Presenting within 2 weeks & $\begin{array}{c}\text { Achilles tendon Avulsions from } \\
\text { calcaneum }\end{array}$ \\
\hline Age 20-65 years & Open injury \\
\hline & $\begin{array}{c}\text { Associated with other injuries in } \\
\text { the ipsilateral lower extremity }\end{array}$ \\
& $\begin{array}{c}\text { Late presentation [Chronic } \\
\text { ruptures]- More than 2 weeks }\end{array}$ \\
\hline
\end{tabular}

Diagnosis of TA rupture was based on clinical examination palpable gap in the Achilles tendon, positive Thompson test [calf squeeze test] and ultrasound examination.

After the inclusion in study patients were randomized to either surgical treatment or non-surgical treatment. Randomization done using computer generated sealed envelops. Patients, treating surgeons and evaluators were not blinded to treatment groups. All the patients in this study underwent identical treatment except the presence or absence of surgical repair.

\section{Treatment procedure}

\section{Surgical Treatment}

Surgery done with the patient in prone position and tourniquet used for haemostasis. A standard postero-medial incision made and paratenon is included in the skin flap. The cut tendon ends approximated with foot in equinus and the torn ends repaired with No.2 non-absorbable suture with Krackow's suture technique. Circumferential suturing done with interrupted absorbable sutures. Paratenon sutured with absorbable sutures. Skin sutured with prolene.

Above knee posterior back slab was applied with the foot in gravity equines $\left[-30^{\circ}\right]$. After 2 weeks plaster slab removed and functional rehabilitation started. Fifteen [n=15] patients were treated by surgery.

\section{Non-surgical Treatment:}

Patients were treated immediately with above knee plaster with foot in $30^{\circ}$ equinus for 2 weeks. Fifteen [ $\left.n=15\right]$ patients were included in this group. After 2 weeks cast removed and started functional rehabilitation, with the same brace as used in surgical group.

\section{Functional Rehabilitation}

Initially both the groups of the patients were treated with plaster cast. After 2 weeks plaster removed and functional rehabilitation was started. It includes below knee walking brace [Dyna CAM walker] with 3 centimeter heel lift to provide $30^{\circ}$ plantar flexion.

Weight bearing: Protected weight bearing started from $3^{\text {rd }}$ week and progressive weight bearing as tolerated afterwards. ROM Exercises: Active plantar flexion exercises from neutral to $30^{\circ}$ plantar flexion as tolerated.

No active dorsiflexion allowed up to 8 weeks.

\section{Physiotherapy}

ROM Exercises of ankle. Gait training. Strengthening of calf muscles by heel rises bilateral. Proprioception exercises single leg balance

\section{Outcome measures}

The primary outcome measures are calf circumference, ROM ankle, calf muscle strength [muscle endurance], ATRS score functional outcome assessed with ATRS score. The secondary outcomes measured are re-rupture rates and other complications.

Calf circumference is measured $15 \mathrm{~cm}$ from the knee joint line and compared to the uninjured side. ROM ankle measured with standard goniometer. Calf muscle strength measured with calf muscle endurance or single heal rise test [standing on one leg]. Heel rise is measured as height of each heel rise and number of repetitions. All the above parameters are measured on the injured leg as well as normal leg and then compared to normal side. The variable were measured at 3, 6 and 12 months follow-up. All the complications including rerupture were assessed at all the followup visits. Re-rupture was diagnosed clinically - by palpable gap, positive Thompson test and loss of plantar flexion strength. US/MRI is used if clinical examination was inconclusive.

\section{Statistical analysis}

All the data were analyzed using SPSS 16.0. Descriptive data are reported as - mean and SD and range [minimummaximum]. To compare outcome measures [dependent variables] between 2 groups of patients - calf muscle circumference, ROM, Muscle strength and ATRS score, Mann-Whitney U test is used. Wilcoxon signed rank test is used to compare the outcome measures within the same group at different time intervals. The re-rupture rates [dichotomous variables] are compared using Fisher exact test. A p-Value of $<0.05$ was considered significant.

\section{Results}

Table 2: Demographic characteristics of patients

\begin{tabular}{|c|c|c|c|}
\hline Parameters & Surgical group & $\begin{array}{c}\text { Non surgical } \\
\text { group }\end{array}$ & \begin{tabular}{|c}
$\mathbf{P}$ \\
value
\end{tabular} \\
\hline Age in years $($ Mean \pm SD) & $49.5 \pm 11.5$ & $50.4 \pm 10.8$ & 0.655 \\
\hline \multicolumn{4}{|c|}{ Gender } \\
\hline Males n (\%) & $10(66.7 \%)$ & $9(60.0 \%)$ & \multirow{2}{*}{0.70} \\
\hline Females n (\%) & $5(33.3 \%)$ & $6(40.0 \%)$ & \\
\hline \multicolumn{4}{|c|}{ Injured side } \\
\hline Right n (\%) & $9(60.0 \%)$ & $8(53.3 \%)$ & \multirow{2}{*}{0.71} \\
\hline Left n (\%) & $6(40.0 \%)$ & $7(46.7 \%)$ & \\
\hline \multicolumn{4}{|c|}{ Cause of injury } \\
\hline ADL n (\%) & $11(73.3 \%)$ & $9(60.0 \%)$ & \multirow{2}{*}{0.47} \\
\hline Sports n (\%) & $4(26.7 \%)$ & $6(40.0 \%)$ & \\
\hline \multicolumn{4}{|c|}{ Physical activity } \\
\hline Sedentary n (\%) & $3(20.0 \%)$ & $2(13.3 \%)$ & \multirow{3}{*}{$0.752 *$} \\
\hline Light but mobile n (\%) & $8(53.3 \%)$ & $10(66.7 \%)$ & \\
\hline Heavy work n (\%) & $4(26.7 \%)$ & $3(20.0 \%)$ & \\
\hline
\end{tabular}

In both the groups no significant differences in patient characteristics

\section{Re-rupture}

Re-ruptures occurred in one patient [7\%] in surgically treated group at 10 weeks. There were 2 re-ruptures in non-surgical group which occurred at 13 and 16 weeks. There was no significant difference $[\mathrm{P}=1.000]$ in re-rupture rates between the two groups. 
ROM Ankle: the mean range of plantar flexion was $47^{\circ} \pm 3.81$ [range $40-53^{\circ}$ ] in the operative group and $48.60^{\circ} \pm 3.5$ [range $\left.42-55^{\circ}\right]$ in the non-operative group. The mean range of dorsi flexion was $15^{\circ} \pm 6.59$ [range $7-30^{\circ}$ ] in the surgical group and $16.4^{\circ} \pm 5.80$ [range $6-33^{\circ}$ ]. At 1 year follow up the injured side had less ROM than the normal side. There was no significant difference between the two groups with regard to plantar flexion and dorsi flexion [ $\mathrm{p}=0.34]$. One patient in each group had increased dorsi flexion, indicative of tendon lengthening.

Calf muscle strength: Plantar flexion strength was assessed by Heel rise height test. Plantar flexion strength in the surgical group at 6 months was mean 71mm [range 38 - 101] and mean 81 [range 44-119] at 12 months evaluation. Plantar flexion strength in non-surgical group was mean 64 [range 33-94] at 6 months and 78 [range 29-109] at 1 year follow up. There was no significant difference $[p=0.38$ ] between the 2 groups at 1 year follow up.

Table 3: The comparison of the mean ATRS scores among the two groups at 6 and 12 months

\begin{tabular}{|c|c|c|c|}
\hline & & ATRS scores Mean \pm SD & P value \\
\hline \multirow{2}{*}{$\begin{array}{c}\text { At } 6 \\
\text { months }\end{array}$} & Surgical group & $74.1 \pm 13.41$ Median 72 & \multirow{2}{*}{$0.713^{*}$} \\
\cline { 2 - 4 } & Non surgical group & $71.1 \pm 15.4$ Median 74 & \\
\hline $\begin{array}{c}\text { At 12 } \\
\text { months }\end{array}$ & Surgical group & $87.2 \pm 15.0$ Median 89 & \multirow{2}{*}{$0.412^{*}$} \\
\cline { 2 - 3 } & Non surgical group & $83.1 \pm 15.0$ Median 89 & \\
\hline
\end{tabular}

Note: Mann Whitney U Test used. * No significant difference

Table 4: Comparison of the ATRS scores within the same groups at 6 and 12 months

\begin{tabular}{|c|c|c|c|}
\hline & At 6 months & At 12 months & P value \\
\hline Surgical group & $\begin{array}{c}74.1 \pm 13.41 \\
\text { Median } 72\end{array}$ & $\begin{array}{c}87.2 \pm 15.0 \\
\text { Median } 89\end{array}$ & $0.001 *$ \\
\hline \multirow{2}{*}{ Non surgical group } & $\begin{array}{c}71.1 \pm 15.4 \\
\text { Median } 74\end{array}$ & $\begin{array}{c}83.1 \pm 15.0 \\
\text { Median } 89\end{array}$ & $0.001 *$ \\
\hline
\end{tabular}

Note: Wilcoxon signed rank test used, *significant difference ATRS score improved over time within both the groups.

Table 5: Complications of treatment in both the groups

\begin{tabular}{|c|c|c|}
\hline & Surgical group & Non-surgical group \\
\hline Re-rupture & 1 & 2 \\
\hline Skin related complications & 3 & 2 \\
\hline Deep wound infection & 1 & \\
\hline Wound-failure to heal & 2 & \\
\hline Scar adhesion & 1 & \\
\hline Hypertrophic scar & 2 & \\
\hline Sural nerve damage & 3 & 2 \\
\hline DVT & 1 & 1 \\
\hline Over lengthening of tendon & 0 & \\
\hline Achilles tendon contracture & 1 & \\
\hline $\begin{array}{c}\text { Non-healing of the tendon } \\
\text { [Palpable gap] }\end{array}$ & 0 & \\
\hline
\end{tabular}

Skin related complications- Pressure sores, blisters, fungal infections and superficial wound infections.

\section{Discussion}

Rehabilitation can be functional [mobilization] or nonfunctional [immobilization]. Functional rehabilitation can be classified into controlled early range of motion of joints or early weight bearing or a combination of the two.

Historically the published clinical trials have shown increased re-rupture rates range from 9 to $21 \%$ with non-operative treatment and 1.7 to $10 \%$ for operative treatment ${ }^{[9,10,1,3]}$. The studies which used accelerated functional rehabilitation protocol re-rupture rates were equivalent between operative and non-operative treatment without the added risk of wound related complications [11, 3, 9]. This study suggests that the operative treatment and non-operative treatment of acute Achilles tendon rupture were equal [equivalent] with regard to re-rupture rate when non-operative treatment includes functional rehabilitation - early ROM and weight bearing.

The re-rupture rate in our study is $7 \%(1 / 15)$ with surgical treatment and $13 \%(2 / 15)$ with conservative treatment but no stastically significant difference between the two groups. The re-rupture rates in our study are consistent with similar studies shown in table No.5. One re-rupture in the surgical group occurred in a patient following deep wound infection at 10 weeks, which was treated by augmented TA repair. Two patients in the conservatively treated group had a re-rupture at 13 and 16 weeks during activities of daily living - history of fall. One is treated by surgery and other by extended immobilization, all went on to heal.

Table 6: Re-rupture rates:- Comparison of our study with other studies

\begin{tabular}{|c|c|c|c|}
\hline & $\begin{array}{c}\text { Surgical } \\
\text { Group }\end{array}$ & $\begin{array}{c}\text { Non-surgical } \\
\text { Group }\end{array}$ & $\begin{array}{c}\text { P } \\
\text { Value }\end{array}$ \\
\hline Nilssan-Helander 2010 & $2[4 \%]$ & $6[12 \%]$ & 0.377 \\
\hline Wiltis K 2010 & $2[2.7 \%]$ & $3[4.16 \%]$ & \\
\hline Metz R 2008 & $3[7.1 \%]$ & $5[12.21 \%]$ & 0.590 \\
\hline Olsson N 2013 & $0[0 \%]$ & $5[9.8 \%]$ & 0.060 \\
\hline Present Study 2019 & $1[7 \%]$ & $2[13 \%]$ & 1.000 \\
\hline
\end{tabular}

Complications other than re-rupture were higher in surgically treated patients compared to non-surgical functional treatment. Surgically treated patients developed 15 complications mainly related to skin and wound complications whereas conservatively treated patients had only 8 complications [Table No.4].

The patients in the operated group had a mean ATRS of 74 points [median 72; range 38-99] at 6 months follow up and 87 points [median 89; range $37-100$ ] at 12 months follow up. The patients in the non-operative group had mean ATRS of 71 points [median 74; 33-98] at 6 months evaluation and 83 points [median 89 range 45-100] at 1 year follow up. Both groups improved significantly $[\mathrm{P}=0.001]$ over time. There were no significant differences between the 2 groups either at 6 months or 12 months follow up evaluations $[\mathrm{P}=0.713$ and $\mathrm{P}=0.412$ respectively] table no 6 .

Table 6: Comparison of ATRS Score at 6 and 12 months with other studies

\begin{tabular}{|c|c|c|c|c|c|c|}
\hline & \multicolumn{3}{|c|}{6 months evaluation } & \multicolumn{3}{|c|}{12 months evaluation } \\
\hline Study \& ATRS score & Surgical group & Non-surgical & P-Value & Surgical group & Non-surgical & P value \\
\hline Nilsson-Helander 2010 & \multirow{4}{*}{$\begin{array}{c}72 \\
75[31-100]\end{array}$} & \multirow{4}{*}{$\begin{array}{c}71 \\
75[32-100]\end{array}$} & \multirow{4}{*}{0.870} & \multirow{4}{*}{$\begin{array}{c}88 \\
93[30-100]\end{array}$} & \multirow{4}{*}{$\begin{array}{c}86 \\
90[31-100]\end{array}$} & \multirow{4}{*}{0.441} \\
\hline Mean + SD & & & & & & \\
\hline Median [range] & & & & & & \\
\hline $\mathrm{N}=49,48$ & & & & & & \\
\hline Olsson N 2013 & \multirow{4}{*}{$\begin{array}{c}70 \pm 23 \\
75[0-99]\end{array}$} & \multirow{4}{*}{$\begin{array}{c}70 \pm 19 \\
73[33-97]\end{array}$} & \multirow{4}{*}{0.63} & \multirow{4}{*}{$\begin{array}{c}82 \pm 20 \\
89[0-100]\end{array}$} & \multirow{4}{*}{$\begin{array}{c}80 \pm 23 \\
90[2-100]\end{array}$} & \multirow{4}{*}{0.68} \\
\hline Mean +SD & & & & & & \\
\hline Median [range] & & & & & & \\
\hline $\mathrm{N}=47,46$ & & & & & & \\
\hline
\end{tabular}




\begin{tabular}{|c|c|c|c|c|c|c|}
\hline Present study 2019 & \multirow{4}{*}{$\begin{array}{c}74+13 \\
72[38-99]\end{array}$} & \multirow{4}{*}{$\begin{array}{c}71+15 \\
74[33-98]\end{array}$} & \multirow{4}{*}{0.713} & \multirow{4}{*}{$\begin{array}{c}87 \pm 15 \\
89[37-100]\end{array}$} & \multirow{4}{*}{$\begin{array}{c}83 \pm 15 \\
89[45-100]\end{array}$} & \multirow{4}{*}{0.412} \\
\hline Mean +SD & & & & & & \\
\hline Median [range] & & & & & & \\
\hline $\mathrm{N}=15,15$ & & & & & & \\
\hline
\end{tabular}

There was no statistically significant difference between operative and non-operative functional treatment with regard to calf circumference, plantar flexion strength and functional outcomes in our study and comparable with similar studies in the literature [table no 6] ${ }^{[1,3,9,12]}$.

\section{Conclusion}

According to the results of our study non-operative functional treatment is beneficial and reasonable treatment of choice compared to operative treatment, as the re-rupture rates are equivalent between the two groups and avoids complications associated with surgery and is a valid alternative to surgical treatment.

\section{References}

1. Metz R, Verieisdonk EJ, Van der Heijden, Clevers GJ, Hammacher ER, Vernofstad MH, et al. Acute Achilles Tendon rupture: minimally invasive surgery versus nonoperative treatment with immediate full weight bearing a randomized controlled trial. Am J Sports Med. 2008;36(9):1688-94.

2. Soroceanu A, Sidhwa F, Arabi S, Kaufman A, Glazebrook M. Surgical versus nonsurgical treatment of acute Achilles tendon rupture: A meta-analysis of randomized trials. J Bone Joint Surg Am. 2012;94(23):2136-2143.

3. Willits K, Amendola A, Bryant D, Mohtadi NG, Giffin JR, Fowler $\mathrm{P}$, et al. Operative versus non-operative treatment of acute Achilles tendon ruptures: a multicenter randomized trial using accelerated functional rehabilitation J Bone Joint Surg Am. 2010:92(17):276775.

4. Saleh M, Marshall PD, Senior R, MacFarlane A. The Sheffield splint for controlled early mobilization after rupture of the calcaneal tendon: A prospective randomized comparison with plaster treatment. J Bone Joint Surg Br. 1992;74(2):206-209.

5. Mortensen NH, Skov O, Jensen PE. Early motion of the ankle after operative treatment of a rupture of the Achilles tendon: a prospective randomized clinical and radiographic study. J Bone Joint Surg Am. 1999;81(7):983-990.

6. Costa ML, MacMillan K, Halliday D, Chester R, Shepstone L, Robinson AH, et al. Randomized controlled trials of immediate weight-bearing mobilization for rupture of the tendo Achilles. J Bone Joint Surg Br. 2006;88:69-77.

7. Kangas J, Pajala A, Ohtonen P, Leppilahti J. Achilles Tendon elongation after rupture repair: a randomized comparision of 2 postoperative regimens. Am J Sports Med. 2007;35:59-64.

8. Suchak AA, Bostick GP, Beaupre LA, Durand DC, Jomha NM. The influence of early weight bearing compared with non-weight bearing after surgical repair of the Achilles tendon. J Bone Joint Surg Am. 2008;90(9):1876-1883.

9. Nilsson-Helander K, Silbernagel KG, Thomee R, et al. Acute Achilles tendon rupture: A randomized, controlled study comparing surgical and non-surgical treatments using validated outcome measures. Am J Sports Med.
2010;38(11):2186-2193.

10. Moller A, Astron M, Westlin N. Increasing incidence of Achilles tendon rupture. Acta Orthop Scand. 1996;67:479-81.

11. Twaddle BC, Poon P. Early motion for Achilles tendon ruptures: is surgery important? A randomized prospective study. Am J Sports Med. 2007;35:2033-8.

12. Olsson N, Silbernagel KG, Eriksson BI, et al. stable surgical repair with accelerated rehabilitation versus nonsurgical treatment for acute Achilles tendon ruptures: A randomized controlled study. Am J Sports Med. 2013;41(12):2867-2876. 